\title{
Analisis lesi endo-perio di periapikal melalui radiografi
}

\author{
Chrisna Ardhya Medika ${ }^{1 *}$, Suhardjo Sitam², Lusi Epsilawati²
}

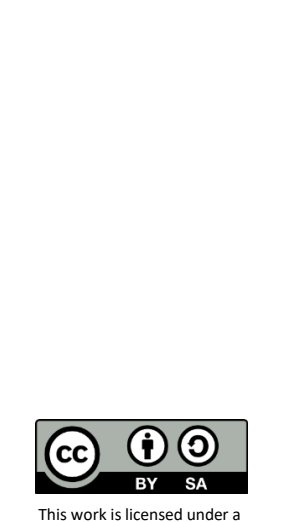

This work is licensed under a
Creative Commons Attribution 4.0
${ }^{1}$ PPDGS Radiologi Kedokteran Gigi, Fakultas Kedokteran Gigi, Universitas Padjadjaran, Bandung, Indonesia, 40132

2 Departemen Radiologi Kedokteran Gigi, Fakultas Kedokteran Gigi, Universitas Padjadjaran, Bandung, Indonesia, 40132

*Correspondence to:

Chrisna Ardhya Medika

冈dentchriest@gmail.com

Received on: June 2019

Revised on: July 2019

Accepted on: August 2019

\section{ABSTRACT}

Objectives: Endodontic lesions and periodontal Installation of Dental Conservation Specialist RSGM lesions that appear together in the same tooth are FKG Padjadjaran University complained that the called endo-perio lesions. This study is aimed to lower left molar was sore and swollen gums had explain further on radiography characteristics of been 3 days. The tooth has been treated by a dentist endo-perio lesions.

Case Report: Case 1, A 21-year-old male patient came to RSGM with a lower left lower back pain complaint. The tooth was once cursed 1 year ago. In the radiographic picture there is a large radiolucent lesion on the alveolar bone around the distal root Case 2, A 25-year-old female patient came to the Patients have taken the drug of mefenamic acid and amoxicillin each one grain.

Conclusion: Periapical radiography is one of diagnostic imaging tools to help establish a more accurate diagnosis of endo-perio lesions.

Keywords: Periapical, endodontic, periodontic, endo-perio lesions Cite this article: Medika CA, Sitam S, Epsilawati L. Analisis lesi endo-perio di periapikal melalui radiografi. Jurnal Radiologi Dentomaksilofasial Indonesia 2019;3(2):27-30. https://doi.org/10.32793/jrdi.v3i2.491

\section{PENDAHULUAN}

Jaringan pulpa dan periodontium memilik hubungan embrionik, anatomis, dan fungsional yang erat. Jaringan pulpa berasal dari papila dental sementara jaringan periodontal berasal dari folike dental; keduanya dipisahkan oleh epitel sarung akar Hertwig (Hertwig's epithelial root sheath). ${ }^{1}$ Hubungan antara lesi endodontik dan periodontal pertama kali dikemukakan oleh Simring \& Goldberg Lesi endodontik adalah inflamasi yang diakibatkan oleh keberadaan agen berbahaya dalam saluran akar gigi. Lesi periodontal merupakan inflamas akibat akumulasi plak dan kalkulus pada permukaan gigi. Lesi endodontik dan periodontal yang muncul serentak pada gigi yang sama disebut lesi endoperio. $^{2}$

Secara anatomis, jaringan periodontal terhubung dengan jaringan pulpa melalui foramen apikal dan kanal lateral. Faktor etiologi seperti bakteri, jamur, dan virus, serta faktor risiko seperti trauma, resorpsi akar, perforasi, dan anomali gig berperan penting dalam inisiasi dan perkembangan lesi endo-perio. Inflamasi pulpa yang bersamaan dengan inflamasi periodontal dapat menyulitkan prosedur diagnosis, rencana perawatan dan memperburuk prognosis. ${ }^{1}$ Tidak semua anatom rongga mulut memiliki posisi yang ideal untuk menghasilkan gambar yang baik. Untuk mengatasi masalah tersebut, ada dua teknik pemotretan yang digunakan untuk memperoleh foto periapikal yaitu teknik biseksi dan paralel. ${ }^{3}$

\section{LAPORAN KASUS}

\section{KASUS 1}

Seorang laki-laki berumur 21 tahun datang ke klinik konservasi RSGM Prof Soedomo FKG UGM dengan keluhan gigi belakang kiri bawah sakit dan ingin dilakukan penambalan ulang pada gigi tersebut. Pada pemeriksaan objektif, gigi 36 terdapat kavitas pada bagian oklusal dengan kedalaman pulpa (Gambar 1A). Hasil tes termal dengan chlorethyl negatif, tes perkusi positif, tes palpasi negatif, dan terdapat mobilitas gigi derajat 1. Pada pemeriksaan radiografis, terlihat bahwa kedalaman kavitas pada gigi 36 sudah mencapai kamar pulpa dan terdapat area radiolusen pada tulang alveolar yang meluas dari bifurkasi gigi $36 \mathrm{ke}$ akar distal (Gambar 1B).

Diagnosis dari kasus ini adalah Gigi 36 nekrosis pulpa disertai dengan bone loss (lesi endodontik primer dengan keterlibatan lesi periodontal sekunder). Rencana perawatannya adalah pembersihan karang gigi, perawatan saluran akar gigi 36 dan restorasi resin komposit kavitas kelas I. Prognosis dari kasus ini adalah baik karena sisa jaringan gigi masih banyak, saluran akar terlihat jelas, dan pasien kooperatif. Sebelumnya pasien dirujuk ke bagian Periodonsia untuk dilakukan pembersihan karang gigi. Pada kunjungan pertama, pasien menandatangani informed consent terlebih dahulu sebelum dimulai perawatan. Sisa tumpatan lama dibuka menggunakan bur bulat kecil, 

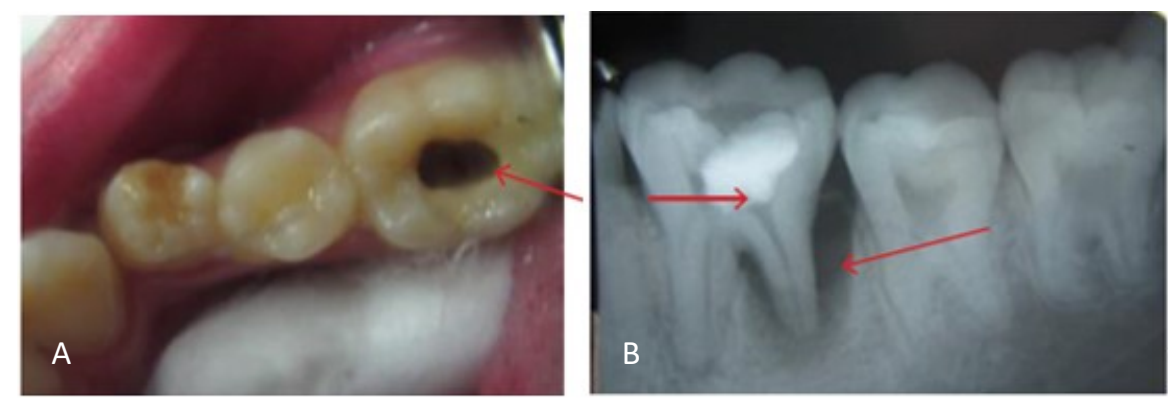

Gambar 1. (A) Keadaan klinis gigi 36 dengan kavitas kelas 1, (B) Gambaran radiografi periapikal pasien pada saat awal kedatangan menunjukkan kavitas yang telah mencapai kamar pulpa, tampak radiolusen pada tulang alveolar pada distal
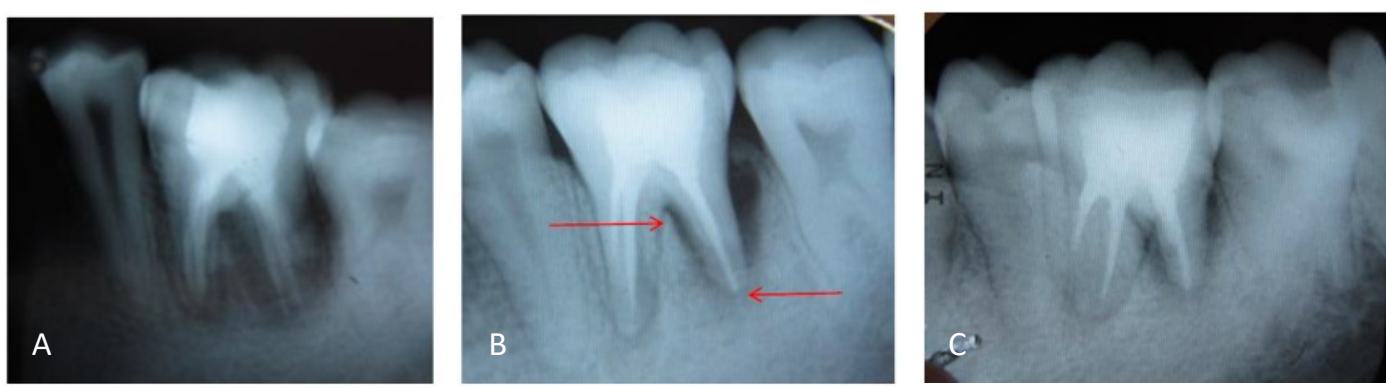

Gambar 2. Radiograf pasca dilakukan perawatan dan pengisian saluran akar, (A) Tampak hasil pengisian telah dilakukan secara hermetis, (B) Saat kontrol pada kunjungan ketiga, terlihat proses penyembuhan pada daerah furkasi dan akar distal, (C) Pada kunjungan keempat tampak penyembuhan tulang alveolar semakin berlanjut pada sisi akar distal

kemudian akses dibuat dengan bur Endoaccess (Dentsply) sampai mencapai ruang pulpa. Pembukaan atap ruang pulpa diteruskan dengan bur Endo $Z$ bur (Dentsply) sampai akses masuk ke orifis melebar dan terbuka sempurna dilanjutkan dengan irigasi dengan $\mathrm{NaOCl} 2,5 \%$ sebanyak $2,5 \mathrm{ml}$.

Pengukuran panjang kerja estimasi didapat dari foto radiograf yaitu dengan cara panjang saluran akar pada radiograf dikurangi 1 sehingga didapatkan panjang kerja estimasi saluran akar mesiobukal $16 \mathrm{~mm}$, mesiolingual $17 \mathrm{~mm}$, distobukal dan distolingual $17 \mathrm{~mm}$, kemudian dilakukan eksplorasi dan negosiasi saluran akar menggunakan $K$-file \#8, \#10, dan \#15. K-File dimasukkan ke dalam saluran akar sepanjang 2/3 panjang kerja estimasi. Saluran akar mesiobukal dan mesiolingual dilakukan preparasi sepanjang 2/3 panjang kerja estimasi menggunakan S1 dilanjutkan S2 dengan panjang 15 $\mathrm{mm}$. Pengukuran panjang kerja dengan menggunakan apex locator dan foto radiografi. Panjang kerja yang diperoleh sebagai berikut untuk akar mesiobukal $16,5 \mathrm{~mm}$, mesiolingual $17,5 \mathrm{~mm}$, distobukal 17,5 mm, distolingual $17,5 \mathrm{~mm}$. Setelah itu, dilanjutkan preparasi saluran akar menggunakan teknik crown down dengan memakai protaper hand use (Dentsply). File terakhir yang digunakan adalah file F2 untuk saluran akar mesial dan file terakhir yang digunakan adalah file \#F3 untuk saluran akar distal. Setiap pergantian alat, saluran akar diirigasi dengan EDTA $15 \%$ dan larutan $\mathrm{NaOCl} 2,5 \%$ sebanyak 2,5 ml. Setelah preparasi saluran akar selesai, saluran akar diirigasi dengan larutan khlorheksidin diglukonat $2 \%$ selama 30 detik, kemudian dibilas dengan larutan salin. Seluruh saluran akar kemudian dikeringkan dengan paper point. Dressing saluran akar dilakukan dengan mencampur serbuk $\mathrm{Ca}(\mathrm{OH})_{2}$ dengan gliserin kemudian dimasukkan ke dalam saluran akar menggunakan lentulo kemudian kavitas ditutup dengan tumpatan sementara (Orafil-G, Pervest Denpro).

Pada kunjungan kedua, pasien tidak mengeluhkan adanya rasa sakit. Pada pemeriksaan objektif, tes perkusi negatif, tes palpasi negatif, mobilitas negatif, dan tumpatan sementara masih baik.Tumpatan sementara dibuka menggunakan diamond bur bulat, saluran akar diirigasi dengan $\mathrm{NaOCl} 2,5 \%$ larutan EDTA (Smear clear, Sybron) dan digenangi larutan klorhexidin $2 \%$ (Bisco) selama \pm 1 menit kemudian dikeringkan dengan paper point. Teknik pengisian dengan teknik single cone, gutta percha yang dipakai sesuai dengan file terakhir \#F2 untuk saluran akar mesial dan gutta percha \#F3 untuk saluran akar distal serta sealer endomethasone. Pemeriksaan hasil pengisian saluran akar dengan pengambilan foto radiograf, hasil menunjukkan pengisian hermetis (Gambar 2A). Pasien diminta untuk kontrol satu bulan kemudian, untuk observasi tulang alveolar bagian akar distal gigi 36 sebelum ditumpat permanen.

Kunjungan ketiga, pasien tidak mengeluhkan rasa sakit. Pada pemeriksaan objektif tes perkusi negatif, tes palpasi negatif, mobilitas negatif, tumpatan sementara masih baik. Selanjutnya pasien melakukan foto radiografis dan terlihat penyembuhan jaringan periodontal (Gambar 2B). Pasien diminta untuk kontrol satu bulan lagi untuk observasi tulang alveolar bagian akar distal gigi 36 sebelum ditumpat permanen.

Kunjungan keempat, pasien tidak mengeluhkan rasa sakit. Pada pemeriksaan objektif tes perkusi negatif, tes palpasi negatif, mobilitas negatif, tumpatan sementara masih baik kemudian dilakukan pengambilan foto radiograf untuk 
observasi kondisi tulang alveolar gigi 36 (Gambar 2C). Hasil radiografis menunjukkan penyembuhan jaringan periodontal. Restorasi akhir dilakukan menggunakan resin komposit packable P60 (3M). Setelah penumpatan resin komposit selesai,dilakukan pemeriksaan oklusi dan artikulasi menggunakan articulating paper. Penyelesaian restorasi resin komposit menggunakan finishing diamond bur, dipoles dengan polishing disk (optidisc, Kerr) dan polishing brush (optishine, Kerr).

\section{KASUS 2}

Seorang pasien perempuan berusia 25 tahun datang ke Instalasi Spesialis Konservasi Gigi RSGM FKG Universitas Padjadjaran mengeluhkan gig geraham kiri bawah terasa sakit dan gusinya bengkak sudah 3 hari. Gigi tersebut pernah dirawat oleh dokter gigi di kota lain, tetapi perawatannya tidak selesai. Pasien telah meminum obat berupa asam mefenamat dan amoksisilin masing-masing satu butir.

Pemeriksaan ekstra oral terlihat wajah asimetris karena adanya pembengkakan pada pip sebelah kiri, sedangkan pemeriksaan intraoral terlihat gigi 36 terdapat tambalan sementara di daerah oklusal, dan gusi bagian bukal mengalam edema (Gambar 3A), kedalaman poket daerah bukal 3-4-3 dan daerah lingual 3-3-3. Tes vitalitas menunjukkan respon negatif, sedangkan tes perkus dan palpasi menunjukkan respon positif.

Pemeriksaan radiologis menunjukkan gambaran radioopak yang menyerupai bahan tambalan dari mahkota sampai kamar pulpa. Aka berjumlah 3 yaitu 1 buah akar mesial dan 2 buah akar distal. Terdapat radiolusen di daerah furkasi, yang hampir mengenai seluruh akar. Keadaan membran periodontal melebar di seluruh permukaan akar (Gambar 3B). Diagnosis untuk gigi
36 adalah nekrosis pulpa disertai periodontitis apikalis simtomatik (AAE, 2013) dan keterlibatan furkasi. Rencana perawatan di bidang endodontik adalah perawatan nekrosis pulpa, dan di bidang periodontik dilakukan bedah periodontal (bila lesi tidak menyembuh). Prognosis perawatan baik karena poket tidak terlalu dalam, lesi terbatas di furkasi, tidak ada perforasi, dan pasien kooperatif.

Tindakan yang dilakukan setelah penandatanganan informed consent adalah pembukaan akses kavitas, dan hasilnya terlihat 3 buah orifis, yaitu 2 di bagian distal dan 1 di bagian mesial yang memanjang dari bukal ke lingual (Gambar 3C). Panjang kerja untuk saluran mesial 22 $\mathrm{mm}$, saluran distobukal $23 \mathrm{~mm}$, dan saluran distolingual $20 \mathrm{~mm}$. Preparasi saluran akar dilakukan dengan teknik crown down menggunakan instrumen rotari MTwo (VDW), dengan master apical file (MAF) \#40 untuk setiap saluran akar dan 5 irigasi menggunakan $\mathrm{NaOCl} 5.25 \%$. Kalsium hidroksida dipilih sebagai medikamen saluran akar, dengan penggantian berkala setiap 14 hari.

Tindakan scalling dan root planning juga telah dilakukan oleh bagian Periodonsia. Pengisian saluran akar dilakukan setelah tiga kali penggantian medikamen secara berkala, dengan teknik continuous wave. Uji coba dilakukan terlebih dahulu sebelum pengisian, dengan gutta percha MTwo \#40 sesuai dengan MAF (Gambar 4A). Saluran akar diirigasi dan dikeringkan, setelah itu dilanjutkan dengan obturasi menggunakan teknik continuous wave, yaitu gabungan antara vertical compaction dan backfill (DiaDent). Pembersihan kavitas dari sisa sealer dan gutta percha, kemudian ditutup dengan SDR (Surefill SDR Flow, Dentsply Chaulk) dan tambalan sementara (Cavit, 3M ESPE, USA). Hasil pengisian dikonfirmasi dengan pemeriksaan radiologi (Gambar 4B).
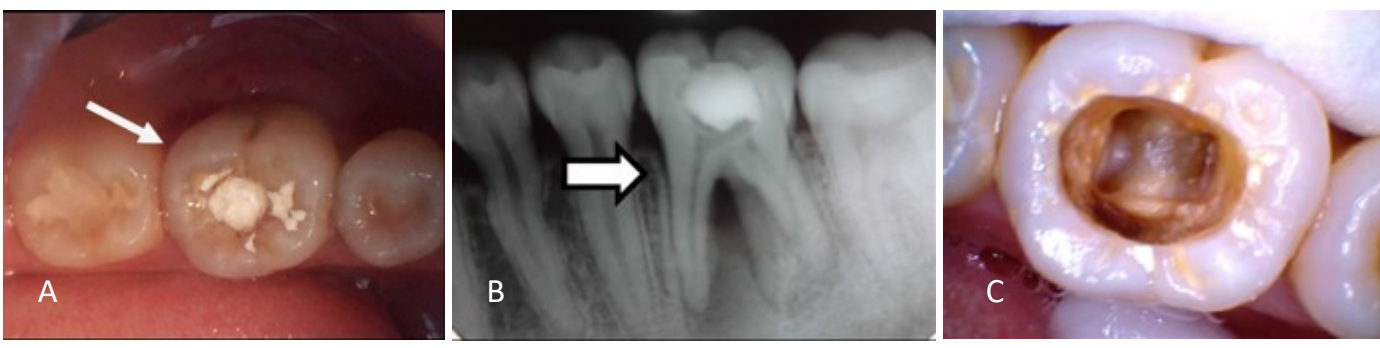

Gambar 3. Kondisi awal gigi pasien saat kedatangan dan setelah dilakukan preparasi, (A) Keadaan awal gigi 36 tampak adanya tumpatan pada oklusal, (B) Secara radiografis tampak lesi radiolusen di furkasi dan apikal disertai pelebaran membran di sepanjang akar, (C) Keadaan gigi setelah dilakukan preparasi akses
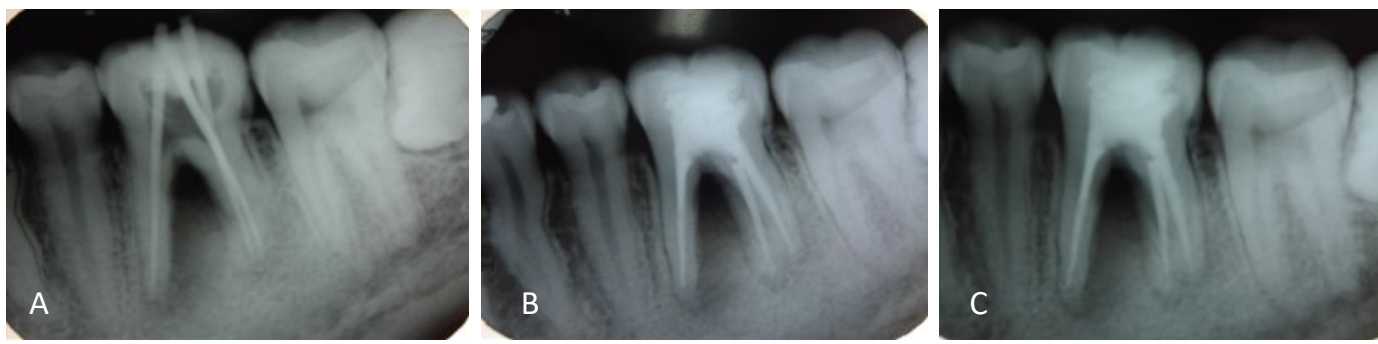

Gambar 4. (A) Radiograf gigi 36 saat dilakukan uji coba pengisian dengan menggunakan gutta percha dan (B) saat telah dilakukan pengisian tetap, (C) Keadaan gigi saat kunjungan kontrol satu minggu kemudian 
Kontrol pengisian dilakukan satu minggu kemudian, hasil dari pemeriksaan subyektif, pasien tidak ada keluhan. Pemeriksaan perkusi (-), tekan (), palpasi (-), dan tidak ada mobiliti, kedalaman 6 poket daerah bukal berkurang menjadi 3-3-3 tetapi masih terdapat sangkutan di daerah furkasi.

Dilakukan foto kontrol pengisian untuk melihat keadaan akar dan jaringan periapikal. Hasilnya menunjukan pengisian yang hermetis, tetapi gambaran radiolusen di furkasi masih tetap ada (Gambar 4C). Resin komposit kelas I dipilih sebagai restorasi pasca endodontik, kemudian pasien dirujuk ke bagian periodonsia untuk perawatan lesi di bagian furkasi.

\section{DISKUSI}

Hubungan antara penyakit pulpa dan periodontal utamanya terjadi karena adanya anatomi dan vaskular yang berdekatan; hubungan ini dapat terlihat dari pemeriksaan radiologis, histologis, dan gejala klinis. ${ }^{4}$ Patosis pulpa sebagai penyebab penyakit periodontal menjadi perhatian khusus pada beberapa dekade. Hasil degeneras pulpa berupa debris nekrotik, produk bakteri, dan toksin masuk ke foramen apikal, dan menyebabkan destruksi jaringan periodontal di apikal dan berpotensi bermigrasi ke margin gusi. ${ }^{4}$ Ketika penyakit pulpa telah berkembang lebih lanjut, inflamasi akan meluas dan berefek ke perlekatan periodontal yang terdekat. Proses inflamasi in sering menyebabkan disfungsi ligamen periodontal, resorpsi tulang alveolar, sementum, bahkan dentin. ${ }^{4}$

Lesi endo-perio memiliki gambaran khas yaitu adanya keterlibatan pulpa dan penyakit periodonta pada gigi yang sama. ${ }^{3}$ Beberapa gejala dan tanda lesi endo-perio di antaranya: rasa sakit, pembengkakan, terbentuk poket, mobiliti, perkusi dan palpasi, tes pulpa (tes termal dan kavitas), dan interpretasi radiografi. ${ }^{2} \mathrm{Hal}$ ini sesuai dengan adanya rasa sakit pada gigi yang dikeluhkan oleh pasien serta adanya pembengkakan gusi sejak 3 hari sebelum kedatangan. Pemeriksaan intra oral pun terlihat adanya poket pada daerah bukal. Berdasarkan klasifikasi Simon et al tentang lesi endo -perio, kasus gigi 36 termasuk ke dalam lesi endo primer yang disertai keterlibatan periodontal sekunder (Tipe 2). 2,3,5,6,7 Kontaminasi saluran akar terjadi karena adanya karies, dan kebocoran daerah koronal. Keadaan pulpa yang nekrosis akan 7 memicu respon inflamasi pada ligamen periodontal, foramen apikal, dan tulang alveolar di bawahnya. ${ }^{2,7,8}$ Menurut Storrer, prosedur yang direkomendasikan untuk lesi endo-perio tipe 2 ini adalah perawatan endodontik dengan medikamen kalsium hidroksida yang diganti secara berkala, dan diikuti dengan terapi periodontal non bedah. ${ }^{7}$ Terapi periodontal tidak dilakukan setelah perawatan endodontik selesai karena terdapat perbaikan kedalaman poket setelah beberapa bulan pasca perawatan. Hal ini sesuai dengan pernyataan dari Torabinejad bahwa defek periodontal yang disebabkan oleh infeksi pulpa dapat diperbaiki cukup dengan cleaning dan shaping yang adekuat serta pengisian saluran akar yang hermetis. ${ }^{1}$ Kalsium hidroksida dipilih sebagai medikamen tunggal pada kasus ini karena memiliki efek antimikroba, serta mampu menginduksi perbaikan daerah periapikal. ${ }^{9}$ Pengisian saluran akar dapat dilakukan meskipun belum terlihat perbaikan pada lesi karena sudah tidak terdapat keluhan dari pasien, ditandai dengan pemeriksaan subyektif dan obyektif yang memberikan respon negatif.

Pemeriksaan radiografi periapikal merupakan indikasi utama pada perawatan lesi ini, tujuan dari pembuatan radiograf ini adalah : a) Untuk mendeteksi infeksi/ inflamasi bagian apical, b) Penilaian terhadap kondisi periodontal, c) Setelah adanya truma pada gigi dan berhubungan dengan tulang alveolar, d) Penilaian kehadiran dan posisi dari gigi yang belum erupsi, e) Penilaian mofrologi akar sebelum pencabutan/ekstraksi, f) Penilaian sebelum dan setelah operasi apical, g) Evaluasi mendetail dari kista apikal dan lesi lainnya dalam tulang alveolar, h) Evaluasi setelah operasi implan. ${ }^{10}$

\section{SIMPULAN}

Lesi endo-perio umumnya menampilkan gambaran kerusakan tulang alveolar yang luas meliputi daerah periapikal hingga daerah furkasi. Hal ini merupakan ciri khas terjadinya lesi endoperio. Lesi ini merupakan abses dengan konten isi radiolusen dan batas tidak jelas (difus). Radiografi yang dipilih pada evaluasi perawatan lesi ini adalah radiografi periapikal.

\section{DAFTAR PUSTAKA}

1. Kumar R, Patil S, Hoshing U, Medha A, Mahaparale R. Nonsurgical endodontic management of the combined endo-perio lesion. Int J Dent Clin. 2011; 3(2): 82-84.

2. Rotstein I, Simon JH. The endo-perio lesion: a critical appraisal of the disease condition, Endodontic Topics. 2006; 13: 34-56.

3. Gopal S, Kumar KP, Shetty KP, Jindal V, M S. Interrelationship of Endodontic-Periodontal Lesions - An Overview. Indian J Dent Sci. 2011;3(2):55-9.

4. Torabinejad M, Rotstein I. Endodontic-Periodontic Interrelationship. Endodontics Principles and Practice. 2015. p. $106-20$.

5. Shenoy N, Shenoy A. Endo-perio lesions: diagnosis and clinical considerations. Ind J Dent Res. 2010; 21(4): 579-585.

6. Peeran SW, Thiruneervannan M, Abdalla KA, Mugrabi $\mathrm{MH}$ Endo-Perio Lesions. Int J Sci Technol Res. 2013;2(5):268-72

7. Gulabivala K, Darbar U, Ng Y-L. The perio-endo interface. Endodontics. 2014. p. 299-328. Parolia A, Gait TC, Porto ICC. Mala K. Endo-Perio Lesion: a Dilemma from 19th until 21st century. J Interdiscip Dent. 2013;3(1):2-9.

8. Patil VA, Deshpande PS, Shivkumar PT. Endo-perio lesion: interdiciplinary approach. Int J Dent Clin. 2009; 1(1): 32-35.

9. Garg N, Garg A. Endodontic Periodontal Relationship. Textbook of Endodontics. 2014. p. 413-27

10. Goaz, P.W. dan S.C. White. Oral Radiology Principles and Interpretation, 7rd. edition. St. Louis: The C.V. Mosby Co. 2014 